\title{
Risk Factors for Gastroesophageal Reflux Disease in Saudi Arabia
}

\author{
Ali Mesfer Alkhathami ${ }^{\mathrm{a}}$, Abdulrahman Ahmad Alzahrania, c, \\ Mohammed Abdullah Alzhrani ${ }^{a}$, \\ Obaidallah Buraykan Alsuwat ${ }^{\mathrm{a}}$, Mohammad Eid Mahmoud Mahfouz ${ }^{\mathrm{a}}$, b
}

\begin{abstract}
Background: Gastroesophageal reflux disease (GERD) is one of the most prevalent gastrointestinal tract diseases worldwide. GERD has an effect on the patients' quality of life as well as the health care system that can be prevented by identifying its risk factors among the population. Hence, we applied this study to assess the GERD's risk factors in Saudi Arabia.

Methods: A cross-sectional study was designed to assess the GERD's risk factors among the community of Saudi Arabia. The sample was collected randomly during the period from November to December 2016. Through a self-administered validated GERD questionnaire (GerdQ), GERD was diagnosed. Then, the GERD's risk factors were assessed among all participants. The data were analyzed using Statistical Package for Social Sciences version 21.0; the Student's $t$-test was used to assess the association of GERD and risk factors.
\end{abstract}

Results: A total of 2,043 subjects participated in the study. The characteristics and behaviors of participants statistically significant with GERD were positive family history (39.3\%), obese (body mass index $\left.>30 \mathrm{~kg} / \mathrm{m}^{2}\right)(39.4 \%)$, not performing weekly regular physical activities $\geq 30 \mathrm{~min}(31.1 \%)$ and smoking $(39.3 \%)$. GERD was commonly noticed in participants on analgesics (38.4\%), not taking fibers (37.4\%), drinking tea $(33.4 \%)$, eating greasy $(31.2 \%)$ and fast food $(32.7 \%)$, and these were statistically significant with GERD ( $\mathrm{P} \leq$ $0.05)$.

Conclusion: The characteristics and behaviors associated with GERD in Saudi population are family history of GERD, obesity, sedentary lifestyle and smoking. Other common risk factors correlated with GERD are analgesics intake, no fibers intake, drinking tea, greasy and fast food intake.

Keywords: GERD; Reflux; Risk factors; Saudi Arabia

Manuscript submitted September 7, 2017, accepted September 25, 2017

${ }^{a}$ College of Medicine, Taif University, Taif, Saudi Arabia

${ }^{b}$ King Abdul Aziz Specialist Hospital, Taif, Saudi Arabia

${ }^{c}$ Corresponding Author: Abdulrahman Ahmad Alzahrani, College of Medicine, Taif University, Taif, Saudi Arabia. Email: aakz1415@gmail.com

doi: https://doi.org/10.14740/gr906w

\section{Introduction}

Healthy individuals have a physiological backflow of the gastric contents to the esophagus. When these backflows are associated with an uncomfortable acid regurgitation and/or heartburn, in addition to an injury of the esophageal mucosa at least once per week, that is called gastroesophageal reflux disease (GERD) [1]. GERD has an effect on the patient productivity and quality of life as well as on the health care system [2].

The estimated range of GERD prevalence in Saudi Arabia, based on two studies using the GERD questionnaire (GerdQ) score of $\geq 8$ as the diagnostic criterion of GERD, was between $23.47 \%$ and $45.4 \%[3,4]$. There was one retrospective study reporting a GERD prevalence of $15 \%$ in Saudi Arabia [5].

The GERD is associated with a number of risk factors such as analgesics intake (e.g. non-steroidal anti-inflammatory drugs (NSAIDs)), types of food, types of drinks, smoking, family history, high body mass index (BMI), physical activities, salt or pickles consumption with meals and fast food. These risk factors are mostly related to the lifestyle of the patient [6-9].

There is no previous specific study to assess the GERD's risk factors in all regions of Saudi Arabia. In this study, we aimed to assess the risk factors of GERD among the population of Saudi Arabia.

\section{Methods}

A cross-sectional study was designed to assess the GERD's risk factors among the community of Saudi Arabia. The sample of 2,043 individuals was collected randomly through a self-administered questionnaire, during the period from November to December 2016. Ethical approval was obtained from the research ethics committee in Taif University, Taif, Saudi Arabia (application number: 38-36-0042). The questionnaire included two parts. The first part included questions about the characteristics, behaviors, risk factors and lifestyle of the participant related to GERD. These included BMI, physical activities frequency, type of analgesics used, number of meals per day, most types of food, most types of drinks, improvement with proton pump inhibitors (PPIs) drugs, smoking, family history of GERD, salt or pickles consumption with 
Table 1. Characteristics and Behaviors and GERD in Saudi Participants $(n=2,043)$

\begin{tabular}{|c|c|c|c|c|c|}
\hline \multirow{3}{*}{ Characteristics and behaviors } & \multicolumn{4}{|c|}{ GERD } & \multirow{3}{*}{ P value } \\
\hline & \multicolumn{2}{|c|}{ Negative } & \multicolumn{2}{|c|}{ Positive } & \\
\hline & $\mathbf{n}$ & $\%$ & $\mathbf{n}$ & $\%$ & \\
\hline Family history & 406 & $60.7 \%$ & 263 & $39.3 \%$ & $0.000^{\dagger \dagger}$ \\
\hline Yes & 1,050 & $76.4 \%$ & 324 & $23.6 \%$ & \\
\hline \multicolumn{6}{|l|}{ No } \\
\hline Body mass index & & & & & $0.000^{\dagger \dagger}$ \\
\hline Obese & 265 & $60.6 \%$ & 172 & $39.4 \%$ & \\
\hline Overweight & 409 & $69.2 \%$ & 182 & $30.8 \%$ & \\
\hline Normal & 633 & $75.9 \%$ & 201 & $24.1 \%$ & \\
\hline Underweight & 149 & $82.3 \%$ & 32 & $17.7 \%$ & \\
\hline Physical activities $>30 \mathrm{~min} /$ week & & & & & $0.024^{\dagger \dagger}$ \\
\hline Never & 550 & $68.9 \%$ & 248 & $31.1 \%$ & \\
\hline $1-3$ & 275 & $69.3 \%$ & 122 & $30.7 \%$ & \\
\hline 1 & 410 & $72.7 \%$ & 154 & $27.3 \%$ & \\
\hline$>3$ & 221 & $77.8 \%$ & 63 & $22.2 \%$ & \\
\hline Improvement with PPIs & & & & & $0.000^{\dagger \dagger}$ \\
\hline Yes & 145 & $46.5 \%$ & 167 & $53.5 \%$ & \\
\hline No & 64 & $61 \%$ & 41 & $39 \%$ & \\
\hline Don’t know & 192 & $74.7 \%$ & 65 & $25.3 \%$ & \\
\hline Not used & 1,055 & $77.1 \%$ & 314 & $22.9 \%$ & \\
\hline Smoking & & & & & $0.000^{\dagger \dagger}$ \\
\hline Yes & 215 & $60.7 \%$ & 139 & $39.3 \%$ & \\
\hline No & 1241 & $73.5 \%$ & 448 & $26.5 \%$ & \\
\hline
\end{tabular}

GERD: gastroesophageal reflux disease; PPIs: proton pump inhibitors. ${ }^{\dagger+S t a t i s t i c a l l y ~ s i g n i f i c a n t . ~}$

meals, fast food, using of analgesics and fibers consumption). The second part was the GerdQ, that is a diagnostic tool for the GERD [10]. GerdQ is composed of six questions, four questions about the positive GERD predictors (heartburn, regurgitation, sleep disturbance due to the heartburn and regurgitation and using over the counter (OTC) medications) and two questions about the negative GERD predictors (nausea and epigastric pain).

\section{Data collection}

There is no available validated Arabic GerdQ. So that, the questionnaires were translated properly from English to Arabic and then conducted by trained medical students through interviews with the general population in the malls, hospitals, primary health care centers, universities, and schools. Also, the online questionnaire (website: http://cutt.us/GERDq) was shared through the social media applications such as WhatsApp, Telegram, Twitter, Facebook, and Instagram. Prior to data collection, all participants were informed about the nature of the study and their participation is voluntary, then the electronic consents were obtained from those who agreed to participate in the study. All Saudi participants in the study were over 18 years old.

\section{GerdQ score}

The scoring of GerdQ depends on the frequency of these symptoms during the last week (less than once, once, 2 - 3 times and 4 - 7 times, respectively), where the scores range from 0 to 3 for the positive GERD predictors and reversed order for the negative GERD predictors (3 for none). After summation of the scores, the patient who gets 8 score or more is considered as having GERD [10].

\section{Statistical analysis}

The data were entered using Microsoft Excel 2010, and analyzed using Statistical Package for the Social Sciences program (SPSS) version 0.21. Data analysis included descriptive statistics as well as the Student's $t$-test for comparison between groups. A statistical significance is considered when $\mathrm{P}$ value $\leq$ 0.05 . 


\section{Results}

\section{Characteristics and behaviors}

Two thousand forty-three subjects participated in the study. One thousand three hundred seventy-four $(67.3 \%)$ of the participants did not have a family history of GERD. The mean and standard deviation (SD) of BMI was $26 \pm 6.7 \mathrm{~kg} / \mathrm{m}^{2}$ and among the participants, $8.9 \%$ were underweight, $40.8 \%$ were normal, $28.9 \%$ were overweight and $21.4 \%$ were obese. Among the participants, $39.1 \%$ did not perform weekly regular physical activities $\geq 30 \mathrm{~min}$ and $27.6 \%, 19.4 \%$ and $13.9 \%$ had regular physical activity $\geq 30$ min once a week, $1-3$ times a week and more than three times a week, respectively. In terms of the response to PPIs use, $15.3 \%$ of participants improved, 5.1\% did not improve, $67 \%$ did not use PPIs and $12.6 \%$ did not know the PPIs. The statistically significant differences between GerdQ results and GERD risk factors are documented in Table 1.

\section{Risk factors and lifestyle}

Of the participants, $354(17.3 \%)$ were smokers. The most common type of drinks was tea $(701,34.3 \%)$, followed by coffee $(33.9 \%)$, soft drinks $(18.6 \%)$, citrus juice $(8.5 \%)$ and peppermint $(4.7 \%)$. Half of the participants have eaten three meals daily, $33 \%$ less than three meals and $16.9 \%$ more than three meals. The most common types of food that the participants preferred were greasy $(54 \%)$, spicy $(25.6 \%)$, chocolate $(13.8 \%)$ and tomatoes $(6.7 \%)$. Intakes of fibers, fast food and salt or pickles were $79.6 \%, 42 \%$ and $67 \%$, respectively. Of the participants, $18.4 \%$ were using analgesics regularly $(13.5 \%$ NSAIDs, $51.9 \%$ paracetamol and $3.1 \%$ other types of analgesics).

There were no statistically significant differences between GerdQ results and a number of meals per day and salts or pickles consumption $(\mathrm{P}>0.05)$. The statistically significant differences between GerdQ results and GERD risk factors are documented in Table 2.

\section{Discussion}

GERD was reported to be associated with reflux symptoms among the patients spouse or a direct family member [11]. Several studies showed an association of GERD symptoms with a relevant family history $[9,12-14]$. Our data were identical to these results (Table 1). Two previous studies conducted in Sweden and United Kingdom (UK) have observed evidence of a genetic component of the disease [15, 16]. Other study also showed an association between gene-encoding collagen type III alpha I (COL3A1) and reflux symptoms [17].

In our study, there was an association between GERD symptoms and BMI (Table 1). Although most studies have reported the association between BMI and GERD symptoms, some studies did not support such association [9, 18]. High
BMI is one of the significant risk factors of GERD among Westerners [19]. Also, several other studies conducted worldwide had found an association between obesity or BMI and severity of GERD symptoms [20-22].

There has been a significant relationship between physical activity and GERD, with $\mathrm{P}$ value $\leq 0.05$ (Table 1). The increase in the frequency of physical exercise is correlated with a lower risk of reflux symptoms [23]. Subjects who have GERD symptoms were less active than those with no symptoms [22, 24]. The effect of physical exercise on GERD symptoms in long term had not been addressed previously, and the mechanism of short term effect could be by strengthening of the striated muscle [23]. Thus, further studies are needed to establish the exact role of physical activity as a protective way against GERD symptoms.

There is a significant association between smoking and GERD in our study (Table 1), similar to several previous studies in which the smoking has been identified as a risk factor of GERD $[20,23,25,26]$. The risk of reflux was significantly increased by $70 \%$ among individuals who had smoked daily for more than 20 years [23]. There is an increase in the reflux during the act of smoking and the following minutes after smoking [26]. Also there was a chronic reduction in lower esophageal sphincter which was estimated as a complication of long-lasting smoking [27]. The mechanism by which smoking affects the GERD is through impairing the lower esophageal sphincter action which is an important barrier to acid reflux by decreasing its pressure. Therefore, advising the smoker patient to quit smoking is justified $[26,27]$.

The causal role of particular foods or drinks in the etiology of heartburn or regurgitation is still unclear [20]. In our study, the GERD is more prevalent among tea consumers. It has been shown that drinking tea including green tea is one of the factors associated with GERD [24, 28]. There was a negative association between coffee and GERD symptoms [23,24], while in another study, there was a role of coffee in increasing the GERD symptoms [29]. However, the coffee consumption is a risk factor for GERD relapsing after treatment with PPIs [30]. Giving the fact that many soft drinks are highly acidic, a change in the intra-esophageal PH may precipitate a GERDlike symptom, which may also increase the acid load in the stomach leading to increased probability of gastroesophageal reflux [31].

There was not a significant relationship between numbers of meals per day and GERD symptoms in our study with $\mathrm{P}$ value of 0.497 (Table 2). However, in GERD patients, most gastroesophageal reflux symptoms do occur in the postprandial period, suggesting a relationship between the characteristics and volume of the gastric contents and the possibility of the reflux [32]. An association has been found between the type of food and the GERD symptoms: it has been reported that there are significantly higher daily intakes of fat and saturated fatty acids in GERD patients compared with the healthy individual [33]. Regular intake of chocolate induces the gastric acid reflux with increasing lower esophageal exposure to acid. Spicy foods might as well induce heartburn, but the mechanism has not known yet [34]. The consumption of fast food is considered as a risk factor for acid reflux $[35,36]$. In this study, we found a significant relationship between the type of food and 
Table 2. Lifestyle and GERD in Saudi Participants $(n=2,043)$

\begin{tabular}{|c|c|c|c|c|c|}
\hline \multirow{3}{*}{ Risk factors and life style } & \multicolumn{4}{|c|}{ GERD } & \multirow{3}{*}{ P value } \\
\hline & \multicolumn{2}{|c|}{ Negative } & \multicolumn{2}{|c|}{ Positive } & \\
\hline & $\mathbf{n}$ & $\%$ & $\mathbf{n}$ & $\%$ & \\
\hline Type of drinks & & & & & $0.000^{\dagger \dagger}$ \\
\hline Tea & 467 & $66.6 \%$ & 234 & $33.4 \%$ & \\
\hline Soft drinks & 257 & $67.8 \%$ & 122 & $32.2 \%$ & \\
\hline Peppermint & 67 & $69.8 \%$ & 29 & $30.2 \%$ & \\
\hline Coffee & 525 & $75.8 \%$ & 168 & $24.2 \%$ & \\
\hline Citrus juice & 140 & $80.5 \%$ & 34 & $19.5 \%$ & \\
\hline No. of meals/day & & & & & 0.497 \\
\hline$>3$ meals & 238 & $68.8 \%$ & 108 & $31.2 \%$ & \\
\hline$<3$ meals & 481 & $71.3 \%$ & 194 & $28.7 \%$ & \\
\hline 3 meals & 737 & $72.1 \%$ & 285 & $27.9 \%$ & \\
\hline Type of food & & & & & $0.023^{\dagger \dagger}$ \\
\hline Greasy & 759 & $68.8 \%$ & 344 & $31.2 \%$ & \\
\hline Spicy & 377 & $72.1 \%$ & 146 & $27.9 \%$ & \\
\hline Chocolate & 215 & $76.5 \%$ & 66 & $23.5 \%$ & \\
\hline Tomatoes & 105 & $77.2 \%$ & 31 & $22.8 \%$ & \\
\hline Fibers & & & & & $0.000^{\dagger \dagger}$ \\
\hline No & 261 & $62.6 \%$ & 156 & $37.4 \%$ & \\
\hline Yes & 1,195 & $73.5 \%$ & 431 & $26.5 \%$ & \\
\hline Fast food & & & & & $0.001^{\dagger \dagger}$ \\
\hline Yes & 578 & $67.3 \%$ & 281 & $32.7 \%$ & \\
\hline No & 878 & $74.2 \%$ & 306 & $25.8 \%$ & \\
\hline Salt or pickles consumption & & & & & 0.353 \\
\hline Yes & 966 & $70.6 \%$ & 402 & $29.4 \%$ & \\
\hline No & 490 & $72.6 \%$ & 185 & $27.4 \%$ & \\
\hline Analgesics use & & & & & $0.000^{\dagger \dagger}$ \\
\hline Yes & 231 & $61.6 \%$ & 144 & $38.4 \%$ & \\
\hline No & 1,225 & $73.4 \%$ & 443 & $26.6 \%$ & \\
\hline Type of analgesics & & & & & $0.001^{\dagger \dagger}$ \\
\hline Others & 36 & $57.1 \%$ & 27 & $42.9 \%$ & \\
\hline NSAIDs & 190 & $69.1 \%$ & 85 & $30.9 \%$ & \\
\hline Paracetamol & 738 & $69.6 \%$ & 323 & $30.4 \%$ & \\
\hline None & 492 & $76.4 \%$ & 152 & $23.6 \%$ & \\
\hline
\end{tabular}

GERD: gastroesophageal reflux disease; NSAIDs: non-steroidal anti-inflammatory drugs. ${ }^{\dagger}$ Statistically significant.

GERD symptoms (P value $\leq 0.05)$ and increased risk of reflux in those who consume fast food in a regular pattern (Table 2).

Salt or pickles consumption was not related to GERD symptoms, according to our study (Table 2). However, some studies have shown that pickles and salt have significant relationships with the reflux symptoms [36]. A high intake of highfibers food such as beans, vegetables and fruits is associated with a reduction in GERD and a decrease in its prevalence [37, 38]. Fibers are associated with low levels of acid production, which may act as a protection from GERD [37]. According to the results of this study (Table 2), the prevalence of GERD was higher in those who did not consume dietary fibers in a regular pattern.

In our study, $38.4 \%$ of the patients with GERD are analgesics users, and we found that most of them regularly use NSAIDs (Table 2). So, there is a strong association between GERD and using NSAIDs, which is supported by many studies [39-41]. The symptoms improvement with PPIs in GERD 
patients in this study is $53.5 \%$ (Table 2), implying that these patients are indeed affected by GERD as there are a number of studies demonstrating that the PPIs improve the GERD symptoms rather than other conditions [42-44]. The explanation for the other patients whose symptoms were not improved with PPIs may be so-called "PPIs failure" or "refractory GERD". "PPIs failure" or "refractory GERD" are used to describe conditions after excluding the unresponsiveness of patient to once daily dose of PPIs due to improper use, incompliance and inadequate dose timing of PPIs [45, 46]. These may be also due to our limited over-simplistic understanding of GERD, not a true failure of PPIs [47]. Unfortunately, in our study, we did not have the detailed PPIs information to determine if it is a true PPIs failure.

\section{Conclusion}

In conclusion, we revealed many GERD-associated risk factors in this study. The characteristics and behaviors that are associated with GERD in Saudi population are family history of GERD, obesity, sedentary lifestyle and smoking. Other common risk factors of GERD are analgesics use, low fibers intake, tea drinking, greasy and fast food consumption. There is no association of GERD with the number of meals per day and salt or pickles consumption in Saudi population.

\section{Acknowledgments}

We would like to extend special acknowledgement to Hebatullah Abdulaziz Alshehri, Jumanah Talal Al-Malki, Lojain Abdul Aziz Al-Shehri, Reham Othman Alzahrani and Sara Mohammed Salem Alosaimi, for their valuable efforts and active role in data collection.

\section{Source(s) of Support}

None.

\section{Conflict of Interest}

None.

\section{References}

1. Bredenoord AJ, Pandolfino JE, Smout AJ. Gastro-oesophageal reflux disease. Lancet. 2013;381(9881):19331942.

2. DeVault KR, Castell DO, American College of G. Updated guidelines for the diagnosis and treatment of gastroesophageal reflux disease. Am J Gastroenterol. 2005;100(1):190-200.

3. Binhussein M, Alamoudi A, Bajawi A, Alghafis M, Baz M, Bakhsh R, et al. Prevalence of gastroesophageal reflux in western region of Saudi Arabia. Saudi J Gastroenterol. 2016;22(7):pS13. http://www.saudijgastro.com/article. asp?issn $=1319-3767$; year $=2016$; volume $=22 ;$ issue $=7$; spa ge $=1$; epage $=24$; aulast $=$.

4. Almadi MA, Almousa MA, Althwainy AF, Altamimi AM, Alamoudi HO, Alshamrani HS, Alharbi OR, et al. Prevalence of symptoms of gastroesopahgeal reflux in a cohort of Saudi Arabians: a study of 1265 subjects. Saudi J Gastroenterol. 2014;20(4):248-254.

5. Al-Humayed SM, Mohamed-Elbagir AK, Al-Wabel AA, Argobi YA. The changing pattern of upper gastro-intestinal lesions in southern Saudi Arabia: an endoscopic study. Saudi J Gastroenterol. 2010;16(1):35-37.

6. Wong WM, Lam KF, Lai KC, Hui WM, Hu WH, Lam CL, Wong NY, et al. A validated symptoms questionnaire (Chinese GERDQ) for the diagnosis of gastro-oesophageal reflux disease in the Chinese population. Aliment Pharmacol Ther. 2003;17(11):1407-1413.

7. Mahadeva S, Raman MC, Ford AC, Follows M, Axon AT, Goh KL, Moayyedi P. Gastro-oesophageal reflux is more prevalent in Western dyspeptics: a prospective comparison of British and South-East Asian patients with dyspepsia. Aliment Pharmacol Ther. 2005;21(12):1483-1490.

8. Jarosz M, Taraszewska A. Risk factors for gastroesophageal reflux disease: the role of diet. Prz Gastroenterol. 2014;9(5):297-301.

9. Saberi-Firoozi M, Khademolhosseini F, Yousefi M, Mehrabani D, Zare N, Heydari ST. Risk factors of gastroesophageal reflux disease in Shiraz, southern Iran. World J Gastroenterol. 2007;13(41):5486-5491.

10. Jones R, Junghard O, Dent J, Vakil N, Halling K, Wernersson B, Lind T. Development of the GerdQ, a tool for the diagnosis and management of gastro-oesophageal reflux disease in primary care. Aliment Pharmacol Ther. 2009;30(10):1030-1038.

11. Diaz-Rubio M, Moreno-Elola-Olaso C, Rey E, Locke GR, 3rd, Rodriguez-Artalejo F. Symptoms of gastro-oesophageal reflux: prevalence, severity, duration and associated factors in a Spanish population. Aliment Pharmacol Ther. 2004;19(1):95-105.

12. Wright RA, Hurwitz AL. Relationship of hiatal hernia to endoscopically proved reflux esophagitis. Dig Dis Sci. 1979;24(4):311-313.

13. Dent J, El-Serag HB, Wallander MA, Johansson S. Epidemiology of gastro-oesophageal reflux disease: a systematic review. Gut. 2005;54(5):710-717.

14. Locke GR, 3rd, Talley NJ, Fett SL, Zinsmeister AR, Melton LJ, 3rd. Risk factors associated with symptoms of gastroesophageal reflux. Am J Med. 1999;106(6):642-649.

15. Zheng Z, Nordenstedt H, Pedersen NL, Lagergren J, Ye W. Lifestyle factors and risk for symptomatic gastroesophageal reflux in monozygotic twins. Gastroenterology. 2007;132(1):87-95.

16. Cameron AJ, Lagergren J, Henriksson C, Nyren O, Locke GR, 3rd, Pedersen NL. Gastroesophageal reflux disease in monozygotic and dizygotic twins. Gastroenterology. 2002;122(1):55-59.

17. Asling B, Jirholt J, Hammond P, Knutsson M, Walentinsson A, Davidson G, Agreus L, et al. Collagen type III 
alpha I is a gastro-oesophageal reflux disease susceptibility gene and a male risk factor for hiatus hernia. Gut. 2009;58(8):1063-1069.

18. Talley NJ, Weaver AL, Zinsmeister AR, Melton LJ, 3rd. Onset and disappearance of gastrointestinal symptoms and functional gastrointestinal disorders. Am J Epidemiol. 1992;136(2):165-177.

19. Locke GR, 3rd, Talley NJ, Fett SL, Zinsmeister AR, Melton LJ, 3rd. Prevalence and clinical spectrum of gastroesophageal reflux: a population-based study in Olmsted County, Minnesota. Gastroenterology. 1997;112(5):14481456.

20. Nocon M, Labenz J, Willich SN. Lifestyle factors and symptoms of gastro-oesophageal reflux -- a populationbased study. Aliment Pharmacol Ther. 2006;23(1):169174.

21. Hampel H, Abraham NS, El-Serag HB. Meta-analysis: obesity and the risk for gastroesophageal reflux disease and its complications. Ann Intern Med. 2005;143(3):199211.

22. El-Serag HB, Johanson JF. Risk factors for the severity of erosive esophagitis in Helicobacter pylori-negative patients with gastroesophageal reflux disease. Scand J Gastroenterol. 2002;37(8):899-904.

23. Nilsson M, Johnsen R, Ye W, Hveem K, Lagergren J. Lifestyle related risk factors in the aetiology of gastrooesophageal reflux. Gut. 2004;53(12):1730-1735.

24. Murao T, Sakurai K, Mihara S, Marubayashi T, Murakami Y, Sasaki Y. Lifestyle change influences on GERD in Japan: a study of participants in a health examination program. Dig Dis Sci. 2011;56(10):2857-2864.

25. Nouraie M, Radmard AR, Zaer-Rezaii H, Razjouyan H, Nasseri-Moghaddam S, Malekzadeh R. Hygiene could affect GERD prevalence independently: a population-based study in Tehran. Am J Gastroenterol. 2007;102(7):13531360 .

26. Smit CF, Copper MP, van Leeuwen JA, Schoots IG, Stanojcic LD. Effect of cigarette smoking on gastropharyngeal and gastroesophageal reflux. Ann Otol Rhinol Laryngol. 2001;110(2):190-193.

27. Gordon C, Kang JY, Neild PJ, Maxwell JD. The role of the hiatus hernia in gastro-oesophageal reflux disease. Aliment Pharmacol Ther. 2004;20(7):719-732.

28. Somi MH, Farhang S, Mirinezhad K, Jazayeri E, NasseriMoghaddam S, Moayeri S, Yasrebinia S. Prevalence and precipitating factors of gastroesophageal reflux disease in a young population of Tabriz, Northwest of Iran. Saudi Med J. 2006;27(12):1878-1881.

29. Nandurkar S, Locke GR, 3rd, Fett S, Zinsmeister AR, Cameron AJ, Talley NJ. Relationship between body mass index, diet, exercise and gastro-oesophageal reflux symptoms in a community. Aliment Pharmacol Ther. 2004;20(5):497-505.

30. Lopez-Colombo A, Pacio-Quiterio MS, Jesus-Mejenes LY, Rodriguez-Aguilar JE, Lopez-Guevara M, MontielJarquin AJ, Lopez-Alvarenga JC, et al. Risk factors associated with gastroesophageal reflux disease relapse in primary care patients successfully treated with a proton pump inhibitor. Rev Gastroenterol Mex. 2017;82(2):106-
114.

31. Johnson T, Gerson L, Hershcovici T, Stave C, Fass R. Systematic review: the effects of carbonated beverages on gastro-oesophageal reflux disease. Aliment Pharmacol Ther. 2010;31(6):607-614.

32. Emerenziani S, Sifrim D. Gastroesophageal reflux and gastric emptying, revisited. Curr Gastroenterol Rep. 2005;7(3):190-195.

33. Ebrahimi-Mameghani M, Sabour S, Khoshbaten M, Arefhosseini SR, Saghafi-Asl M. Total diet, individual meals, and their association with gastroesophageal reflux disease. Health Promot Perspect. 2017;7(3):155-162.

34. Surdea-Blaga T, Negrutiu DE, Palage M, Dumitrascu DL. Food and Gastroesophageal Reflux Disease. Curr Med Chem. 2017.

35. Chirila I, Morariu ID, Barboi OB, Drug VL. The role of diet in the overlap between gastroesophageal reflux disease and functional dyspepsia. Turk J Gastroenterol. 2016;27(1):73-80.

36. Khodarahmi M, Azadbakht L, Daghaghzadeh H, FeinleBisset C, Keshteli AH, Afshar H, Feizi A, et al. Evaluation of the relationship between major dietary patterns and uninvestigated reflux among Iranian adults. Nutrition. 2016;32(5):573-583.

37. Otles S, Ozgoz S. Health effects of dietary fiber. Acta Sci Pol Technol Aliment. 2014;13(2):191-202.

38. Nam SY, Park BJ, Cho YA, Ryu KH, Choi IJ, Park S, Kim YW. Different effects of dietary factors on reflux esophagitis and non-erosive reflux disease in 11,690 Korean subjects. J Gastroenterol. 2017;52(7):818-829.

39. Eusebi LH, Ratnakumaran R, Yuan Y, SolaymaniDodaran M, Bazzoli F, Ford AC. Global prevalence of, and risk factors for, gastro-oesophageal reflux symptoms: a meta-analysis. Gut. 2017.

40. Yonem O, Sivri B, Ozdemir L, Nadir I, Yuksel S, Uygun Y. Gastroesophageal reflux disease prevalence in the city of Sivas. Turk J Gastroenterol. 2013;24(4):303-310.

41. Ruszniewski P, Soufflet C, Barthelemy P. Nonsteroidal anti-inflammatory drug use as a risk factor for gastro-oesophageal reflux disease: an observational study. Aliment Pharmacol Ther. 2008;28(9):1134-1139.

42. Karim ME, Rahim S, Mahmuduzzaman M, Ghosh DK, Islam A, Ahmed H, et al. Guidelines for the diagnosis and management of gastroesophageal reflux disease. J Shaheed Suhrawardy Med Coll. 2016;8(1):30-33.

43. Yadlapati R, Kahrilas PJ. When is proton pump inhibitor use appropriate? BMC Med. 2017;15(1):36.

44. Scarpignato C, Gatta L, Zullo A, Blandizzi C, Group SA-F, Italian Society of Pharmacology tIAoHG, the Italian Federation of General P. Effective and safe proton pump inhibitor therapy in acid-related diseases - A position paper addressing benefits and potential harms of acid suppression. BMC Med. 2016;14(1):179.

45. Shi Y, Tan N, Zhang N, Xiong L, Peng S, Lin J, Chen $\mathrm{M}$, et al. Predictors of proton pump inhibitor failure in non-erosive reflux disease: A study with impedance-pH monitoring and high-resolution manometry. Neurogastroenterol Motil. 2016;28(5):674-679.

46. Yuan Y, Hunt RH. Evolving issues in the management of 
reflux disease? Curr Opin Gastroenterol. 2009;25(4):342351.

47. Heading RC. Proton pump inhibitor failure in gastro- oesophageal reflux disease: a perspective aided by the Gartner hype cycle. Clin Med (Lond). 2017;17(2):132136. 